\title{
Mudanças microtopográficas na superfície do solo em cultivo de tabaco na Região Sudeste do Paraná - Brasil
}

\section{Microtopographic changes on the soil surface in tobacco crop in the Southeast Region of Paraná - Brazil}

\author{
Valdemir Antoneli, Departamento de Geografia da Universidade Estadual do Centro-Oeste - \\ UNICENTRO, Brasil, vantoneli@unicentro.br \\ (1) https://orcid.org/0000-0002-5942-8330 \\ João Anésio Bednarz, Departamento de Geografia da Universidade Estadual do Centro-Oeste - \\ UNICENTRO, Brasil, joaogeo2013@gmail.com \\ (D) https://orcid.org/0000-0003-0328-1699 \\ Leonardo Menon, Departamento de Geografia da Universidade Estadual do Centro-Oeste - \\ UNICENTRO, Brasil, leonardomenon2019@gmail.com
}

(1)

Resumo: O cultivo do tabaco se tornou uma das principais atividades agrícolas das pequenas propriedades na região sudeste do estado do Paraná - Brasil. Na maior parte dessas propriedades o cultivo é realizado com pouca mecanização, favorecendo assim o desenvolvimento do plantio convencional. Esta forma de cultivo é caracterizada pela exposição e revolvimento periódico do solo. O revolvimento da superfície do solo durante o cultivo cria condições adversas na superfície do solo, modificando a dinâmica hidrogeomofológica da superfície. O objetivo dessa pesquisa foi avaliar a influência das atividades agrícolas na rugosidade superficial do solo, ao longo de um ano em uma área de cultivo do tabaco e como essas mudanças podem interferir na retenção de água no solo. Foram utilizadas parcelas com perfis transversais para identificar como as atividades alteram a microtopografia da superfície do solo no período de safra (setembro a fevereiro) e entressafra (março a agosto). Ao término da pesquisa concluímos que as atividades alteram a rugosidade superficial, interferindo na retenção de água no solo. Durante a colheita do tabaco (dezembro a fevereiro) o agricultor deixou de revolver a superfície do solo e as atividades se intensificam, havendo redução da rugosidade superficial. Neste caso, observamos maior escoamento superficial das entrelinhas durante as chuvas.

Palavras-chave: Dinâmicas hidrogeomorfológicas; Atividades agrícolas; Rugosidade; Safra; Entressafra.

\begin{abstract}
Tobacco crop has become one of the main agricultural activities of small farms in the southeastern region of the state of Paraná - Brazil. In most of these properties, cultivation is carried out with little mechanization, contributing to the development of conventional tillage. This cultivation practice is characterized by the periodic exposure and revolving of the soil. The turning of the soil surface during crop creates adverse conditions on the soil surface, modifying the hydrogeomophological dynamics of the surface. The objective of this research was to evaluate the influence of agricultural activities on the surface roughness of the soil over a year in a tobacco crop area and how these changes can interfere with water retention in the soil. Plots with transversal profiles were used to identify how the activities change the microtopography of the soil surface during the crop period (September to February) and inter-crop season (March to August). At the end of the research, we concluded that the activities change the surface roughness, interfering in the water retention in the soil. During the harvest of tobacco leaves (December to February) the farmer stopped revolving the soil surface and activities intensified, with a reduction in surface roughness. In this case, we observed greater runoff between the lines during the rains.
\end{abstract}

Keywords: Hydrogeomophological dynamics; Agricultural activities; Roughness; Crop; Inter-crop. 


\section{Introdução}

A abertura de novas fronteiras agrícolas no Brasil contribuiu para que o país se tornasse um dos principais produtores agrícolas do mundo. A melhoria na qualidade genética das sementes e abertura de novas áreas agrícolas potencializaram esse avanço (Torres-Rojo et al., 2020). No entanto, o avanço tecnológico da agricultura não é percebido em todas as regiões do Brasil. A agricultura mecanizada convive com fazendas tradicionais, onde práticas rudimentares e mão-de-obra familiar são características dominantes devido à dificuldade no processo de mecanização (Antoneli et al., 2018).

A região sudeste do estado do Paraná enfrenta esse tipo de problema, pois em sua maioria são pequenas propriedades rurais com restrições ao uso do solo. As condições físicas da região como: relevo declivoso, solo rasos e clima ameno, associado às questões econômicas, contribuem para a redução da mecanização dessas áreas, potencializando o cultivo do tabaco. Neste contexto, a maior parte das áreas de tabaco é cultivada com plantio convencional, com pouco uso de práticas conservacionistas.

O plantio convencional se resume a perturbação intensiva do solo através da preparação para o plantio, revolvimento durante $\circ$ cultivo e aração pós-colheita (Montgomery, 2007), atividades estas que podem contribuir com a degradação do solo afetando as funções ecossistêmicas (Choudhury et al., 2014)

O cultivo do tabaco tem um ciclo sazonal que na região sudeste do estado do Paraná é realizado de setembro (transplante) a fevereiro (término da colheita). Após esse período, o agricultor semeia uma cobertura vegetal de inverno, geralmente aveia (Avenca Strigosa). Esta cobertura serve para reduzir a exposição do solo na entressafra e, por conseguinte, a redução dos processos hidroerosivos, além de ser incorporada no solo na safra seguinte como matéria orgânica.

Durante o preparo do solo para o plantio, o agricultor constrói os chamados camalhões (amontoados de solo) para o plantio do tabaco na sequência. Após o transplante das mudas (setembro), o agricultor revolve o solo a cada quinze dias em média até o início de dezembro, quando se inicia a fase da colheita das folhas do tabaco. O revolvimento do solo da entrelinha é realizado para eliminar erva daninha através de equipamentos de tração animal. Já as ervas daninhas do camalhão são eliminadas com a capinagem manual ou aplicação de herbicidas. Destacamos que durante a colheita (dezembro a fevereiro) o solo deixa de ser revolvido.

O revolvimento da superfície do solo durante o cultivo cria condições adversas na superfície, alterando a estrutura do solo (Schillinger et al., 2007) e a hidrologia da superfície (Dabney et al., 2011), que refletem nas taxas de perda de solo (Tocanet e Ciarletti, 2007). O cultivo do tabaco indica altas taxas de perdas de solos (Wood e Worsham, 1986; Slattery, 1997; Antoneli e Thomaz, 2014; Antoneli et al., 2018), tornando-se importante fonte de sedimentos e contaminantes para os corpos hídricos 
(Melquiades et al., 2018; Merten e Minella, 2006). No entanto, a influência do revolvimento do solo na mudança da rugosidade superficial ao longo do cultivo do tabaco é pouco estudada. Destaca-se que a rugosidade da superfície do solo é um índice comum usado para quantificar as características de microrrelevo de superfícies cultivadas (Hansen et al., 1999).

Salienta-se que o entendimento da dinâmica da rugosidade ocasionado pelo manejo do solo é essencial para avaliar a retenção de água (Dan et al., 2018), taxa de infiltração (Zhao et al., 2018) e sua influência na erosão do solo (Dalla Rosa et al., 2012).

Desse modo, parte-se da hipótese de que se há revolvimento do solo e mudanças no uso durante o ano, haverá mudanças na rugosidade superficial e na retenção de água durante o período de safra e entressafra.

Diante do exposto, o objetivo desta pesquisa foi identificar as mudanças na rugosidade superficial do solo no período da safra e entressafra de tabaco e como essas mudanças interferem na retenção de água no solo.

\section{Característica do cultivo do tabaco}

De acordo com a FAO (2018), atualmente cerca de 100 países cultivam tabaco, em uma área aproximada de 4 milhões de hectares, tendo como principais produtores a China em torno de $45 \%$ da produção total e o Brasil com cerca de $12 \%$. A região Sul do Brasil é responsável por $95 \%$ da produção total de tabaco do país. No qual o estado do Rio Grande do Sul produz 47,6\%, Santa Catarina 29\% e Paraná com 21,4\% da produção nacional (DERAL, 2017).

A maior parte das áreas destinadas ao cultivo do tabaco apresentam restrições ao uso, posto isso, o cultivo do tabaco é realizado através de plantio convencional ou plantio com cultivo mínimo, sendo este ainda o mais utilizado. Para o cultivo do tabaco é necessário construir camalhões com cerca de $30 \mathrm{~cm}$ de altura e em média $130 \mathrm{~cm}$ de distância um do outro (Figura 1A). A construção dos camalhões é feita para ajudar no desenvolvimento radicular da planta, auxiliar no escoamento da água e reduzir a saturação do solo. Esta mudança microtopográfica superficial acaba criando um divisor de águas, onde o fluxo laminar se concentra sob o meio da entrelinha, formando um canal efêmero gerando grande quantidade de escoamento superficial e erosão (Antoneli e Thomaz, 2014).

O plantio convencional do tabaco é caracterizado pela exposição constante do solo nos primeiros meses de cultivo, ou seja, não possui cobertura vegetal, estando susceptível aos efeitos pluvioerosivos. No entanto, a morfologia da planta do tabaco exerce influência na cobertura do solo do camalhão e parte da entrelinha. Neste modo de produção é necessária a realização da capinagem para eliminação das ervas daninhas e em alguns casos da utilização de tração animal para descompactação da superfície (Figura 1B). Antoneli et al. (2018) identificaram que o uso de tração animal está condicionado a áreas de declive superior a $20 \%$. Estas práticas acabam por disponibilizar material aos processos erosivos, promovendo mudança na 
microtopografia superficial do solo. Durante a colheita do tabaco, dezembro a fevereiro, o solo deixa de ser revolvido (Figura 1C), no entanto, as atividades de colheita se intensificam.

Após o término da colheita do tabaco (fevereiro), o agricultor remove os camalhões e prepara o solo para semeadura da cobertura vegetal de inverno, geralmente aveia (Avena Strigosa). A cobertura vegetal permanece em evolução até meados dos meses de julho/agosto (Figura 1D), quando é revolvido o solo para que essa vegetação seja incorporada como matéria orgânica. No caso do cultivo mínimo, essa vegetação é dessecada, por meio da utilização de herbicida, formando uma camada de palhaça sobre o solo (Filho et al., 2000).

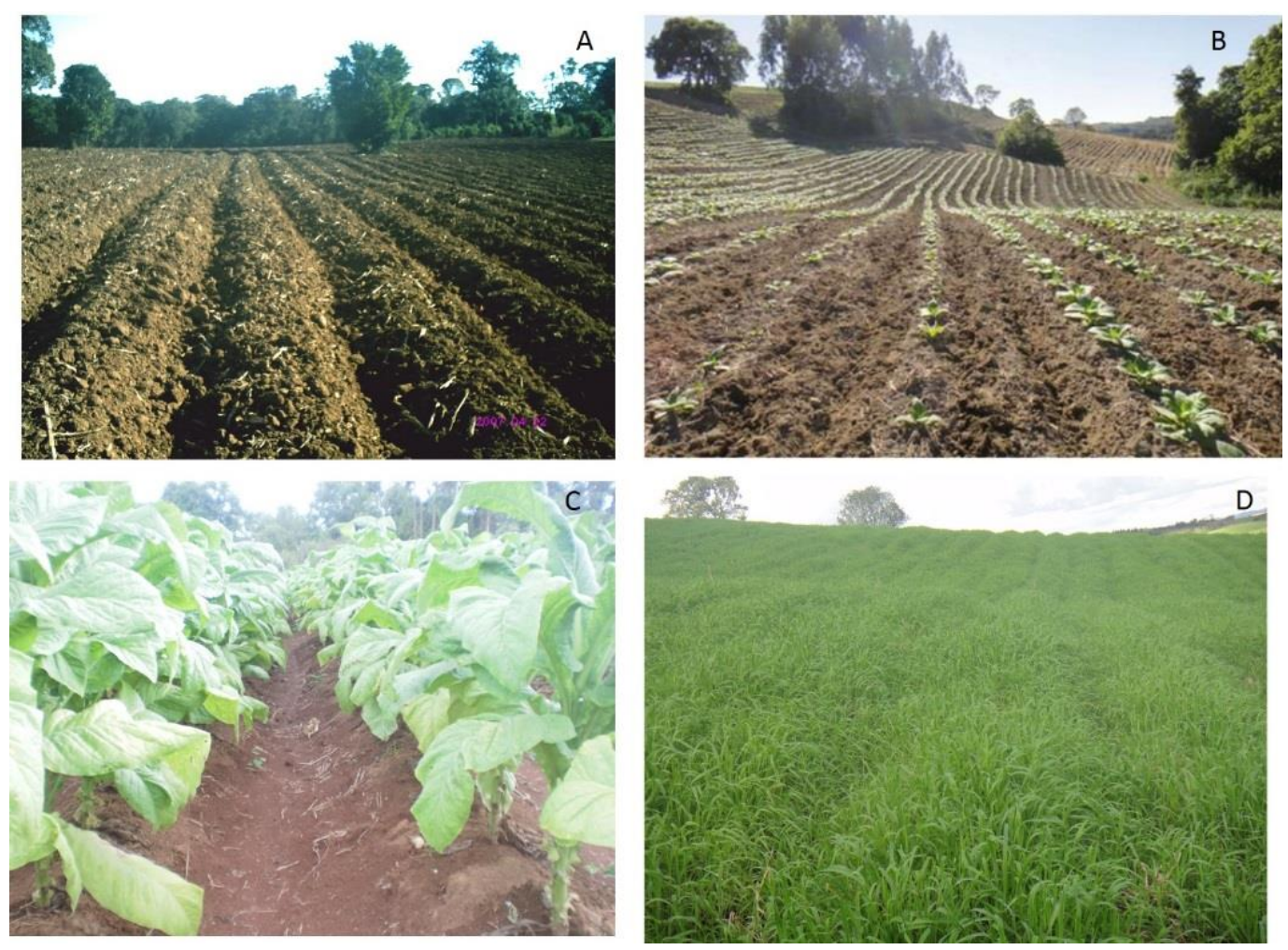

Figura 1: Características da cobertura do solo. A) construção dos camalhões; B) revolvimento do solo; C) colheita do tabaco; D) cobertura vegetal de inverno.

Fonte: Autores (2019)

\section{Metodologia}

Para avaliar a rugosidade, a umidade superficial e exposição do solo, foi utilizada a mensuração dinâmica através de perfis transversais (profilometers) (Fernandes et al., 2001; Fontana et al., 2007). Para estimar a retenção superficial da água (Depth storage) foi empregue a equação proposta por Auerswald (1992). As campanhas de coletas foram realizadas mensalmente totalizando 12 campanhas, sendo 6 durante a safra e 6 na entressafra. As campanhas foram realizadas na primeira semana de cada mês. 


\subsection{Caracterização da área de estudos}

A pesquisa foi realizada na Bacia do Arroio Boa Vista no Município de Guamiranga PR, que está situada entre as coordenadas $25^{\circ} 07^{\prime} 45^{\prime \prime} \mathrm{S}$ e $50^{\circ} 52^{\prime 2} 25^{\prime \prime} \mathrm{W}$ (nascente) e $25^{\circ} 09^{\prime} 21^{\prime \prime} \mathrm{S}$ e $50^{\circ} 54^{\prime} 44^{\prime \prime}$ W (foz) (Figura 2). Esta bacia vem sendo utilizada como área experimental nas últimas duas décadas pelo grupo de pesquisas "Erosão de Solos" da UNICENTRO-PR, devido sua representatividade na região (pequenas propriedades com cultivo de tabaco).

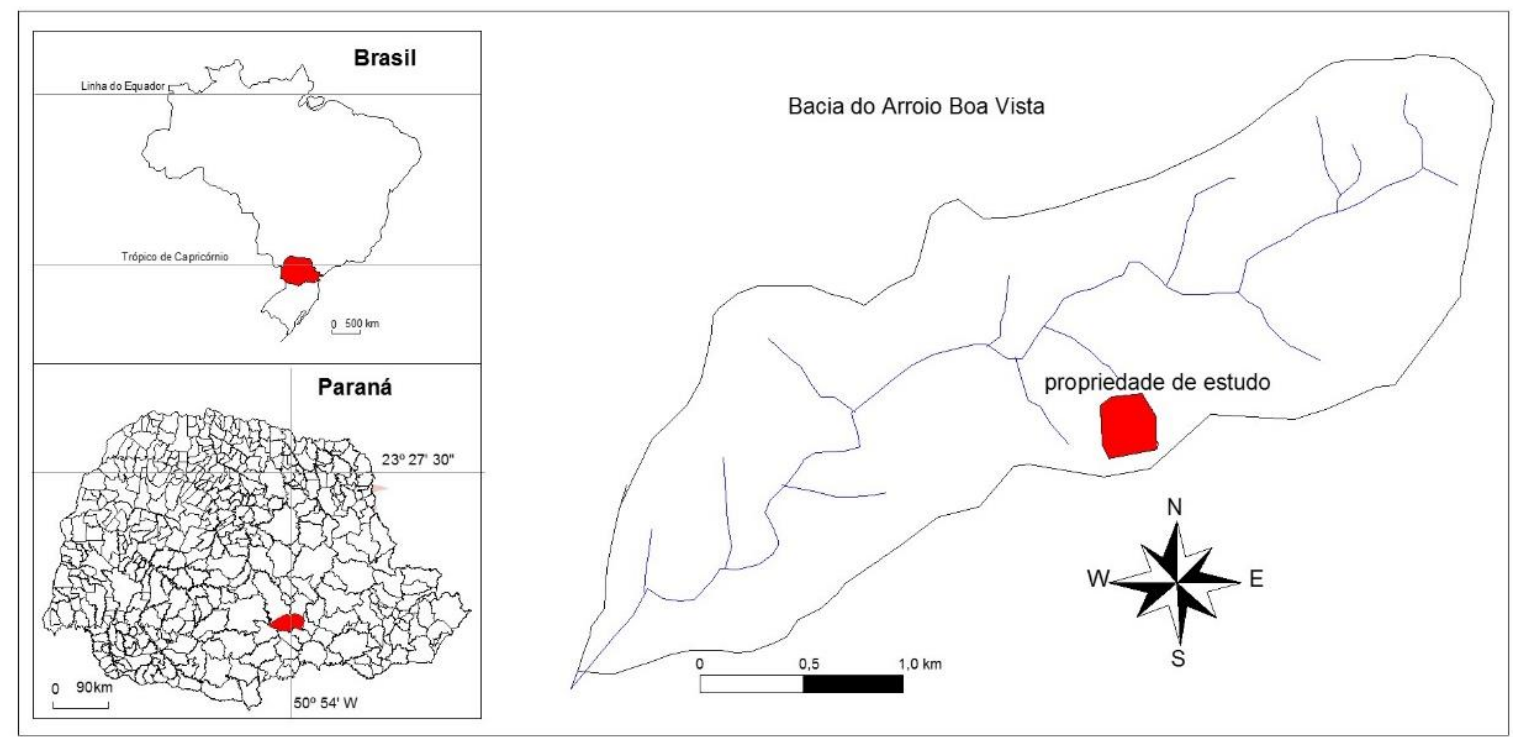

Figura 2: Localização da área de estudos.

Fonte: autores (2019)

A agricultura praticada no âmbito da bacia, segundo a classificação do IAPAR (1995), se insere no conglomerado denominado $\mathrm{C} 13$, que define a região com alta participação de culturas temporárias, principalmente tabaco $(70 \%$ das áreas agrícolas), milho, soja e feijão, sendo utilizada a força do trabalho familiar e de tração animal. É composta, ainda, de pastagens, mata natural de reflorestamento e áreas em pousio associadas à baixíssima utilização de insumos agro-industriais e motomecanização (Antoneli e Thomaz, 2014).

O clima da área é Cfb (subtropical úmido, sem estação seca e com verão inferior a $22^{\circ} \mathrm{C}$ de média). A precipitação é em torno de $2.000 \mathrm{~mm} / \mathrm{ano}$ (dados dos últimos 20 anos de mensuração da pluviosidade na bacia).

A bacia está inserida na borda oeste do Segundo Planalto Paranaense na área de transição, entre os depósitos sedimentares com a Formação Serra Geral. Estas características contribuem para a formação de solos como: Nitossolo, Cambissolo e Neossolo (EMBRAPA, 1999). Na área especifica de monitoramento predomina o Nitossolo Vermelho Distrófico e horizonte $B$ nítico com argila de atividade baixa, imediatamente abaixo do horizonte $A$ ou dentro dos primeiros $50 \mathrm{~cm}$ do horizonte $B$. A textura varia de média a argilosa (Antoneli e Thomaz, 2014). A declividade média da propriedade onde foi realizada a pesquisa é de $18 \%$, classificado como ondulado. 
Neste local, o agricultor cultiva tabaco de forma convencional a 45 anos. Na última década, o agricultor tem adotado algumas práticas conservacionistas como cobertura vegetal de inverno e plantio em curva de nível.

\subsection{Delineamento experimental}

Esta pesquisa focou principalmente na relação entre o revolvimento do solo nas diferentes fases do cultivo do tabaco (safra) e após o cultivo (entressafra), bem como sua relação com a mudança microtopográfica superficial, a qual pode interferir na dinâmica hidrológica da superfície do solo.

\subsection{Calendário das atividades agrícolas realizadas durante o cultivo do tabaco}

A elaboração do calendário das atividades agrícolas permite que se entrelacem informações temporais com o tipo de ferramenta e/ou atividades que foram realizadas ao longo do cultivo do tabaco. Através do calendário agrícola, foi possível avaliar a trafegabilidade dos agricultores, para realizar as atividades diárias para o cultivo do tabaco.

A cada vez que o agricultor adentrou na lavoura de tabaco eram anotados os tipos de atividades e as ferramentas utilizadas. Estas observações foram importantes para saber quantas vezes o solo foi revolvido entre as campanhas das coletas.

\subsection{Exposição do solo}

O percentual de exposição do solo foi avaliado através da adaptação de um quadro de madeira de $1 \times 1 \mathrm{~m}^{2}$ (Antoneli, 2011). Neste quadro, foram feitas subdivisões a cada $10 \mathrm{~cm}$, formando uma malha de 100 quadros menores de $100 \mathrm{~cm}^{2}$ cada. A partir dessa malha, foi realizada a avaliação da exposição do solo em $1 \mathrm{~m}^{2}$.

Os dados foram representados em um croqui, sendo anotado o percentual de exposição de cada quadro menor $\left(100 \mathrm{~cm}^{2}\right)$. Para estipular o percentual de exposição dentro desses quadros menores foi realizada uma avaliação visual, indicando um valor aproximado do percentual de exposição. Ao término da avaliação dos 100 (cem) quadros menores, somamos todos os valores estimados e divididos pelo número total de quadros. Foram realizadas cinco repetições em cada campanha de coleta (mensal) escolhidas ao acaso, totalizando sessenta amostras durante a pesquisa. $O$ resultado do percentual de exposição do referido ponto $\left(1 \mathrm{~m}^{2}\right)$ foi estimado pela equação 1 .

$$
P \exp =\frac{\sum^{n-1} q m}{N q} \quad \text { equação } 1 .
$$

Onde:

Pexp = Porcentagem de exposição do solo em $1 \mathrm{~m}^{2}$;

$\sum^{n-1} q m=$ Somatório da exposição dos quadros menores $\left(100 \mathrm{~cm}^{2}\right)$;

$N q=$ Número total de quadros menores do equipamento. 


\subsection{Rugosidade superficial}

Para monitorar a rugosidade superficial do solo, durante o período de safra e entressafra do tabaco, foi utilizado o método de batimetria (perfis transversais). Para realizar a batimetria foram cravadas quatro estacas de madeira de 01 metro de altura nos camalhões, formando um quadrado de $3 \times 3$ metros (uma parcela de $9 \mathrm{~m}^{2}$ ). Nas bordas do quadro foram utilizadas talas (ripas) de madeira com marcações a cada 10 $\mathrm{cm}$ (Figura 3). Após a fixação dessas madeiras foi confeccionada uma malha com 900 quadros de $10 \times 10 \mathrm{~cm}$. De posse de uma trena (régua), fez-se a mensuração em cada intersecção da malha entre o fio de nylon e a superfície do solo.

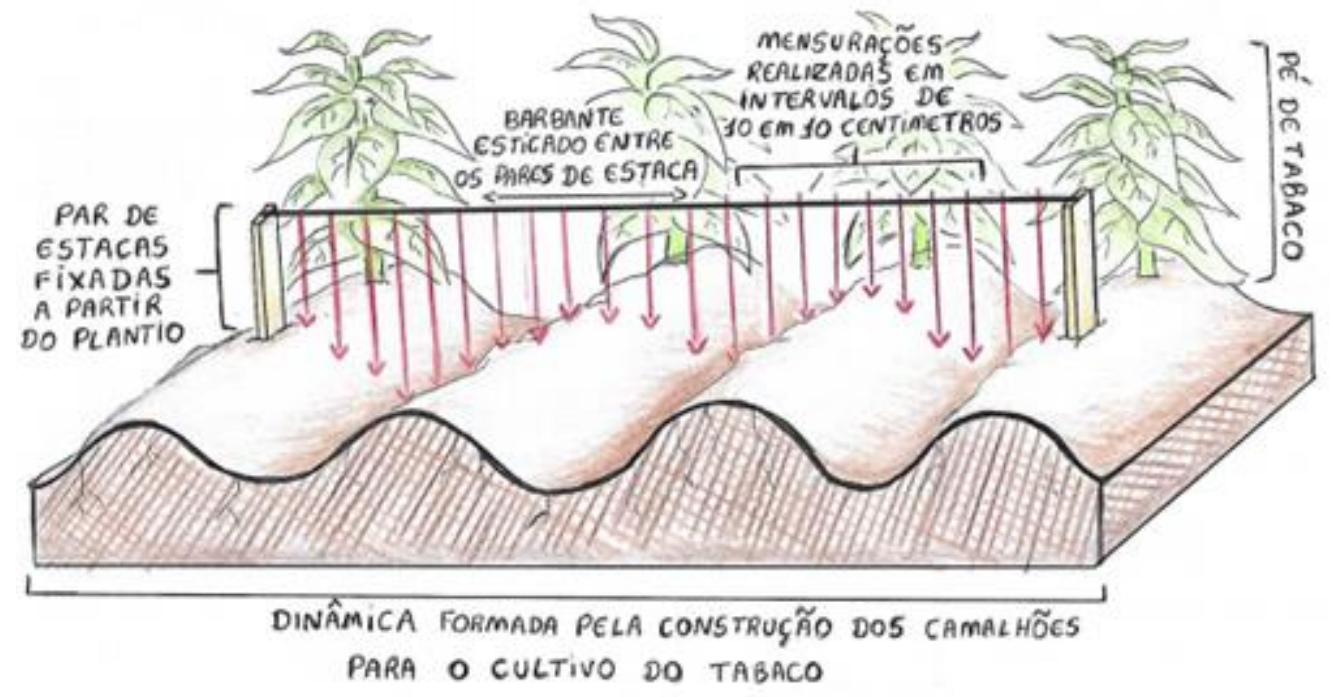

Figura 3: Esboço da coleta dos dados utilizando a técnica de batimetria.

Fonte: Autores (2020)

Após a coleta dos dados, a parcela era revolvida para não interferir nas atividades agrícolas, permanecendo fixas apenas as estacas de madeiras, pois estas serviam de base para o cálculo do rebaixamento e/ou acúmulo de solo nos pontos de coleta.

Na campanha seguinte foi realizada a confecção da parcela novamente para formar a malha para o monitoramento. Ressalta-se que o pesquisador deve tomar cuidado para que a linha seja amarrada no mesmo ponto da última mensuração, ou seja, as intersecções dos fios de nylon devem ser instaladas sempre na mesma posição.

Foram confeccionadas 5 parcelas para o monitoramento da rugosidade superficial. As coletas foram realizadas a cada 30 dias, com início em setembro (confecção do camalhões e plantio) e término em fevereiro (final da colheita) para o período de safra. No período de entressafra as parcelas foram instaladas em março, após o revolvimento dos restos da cultura de tabaco e retiradas em agosto (início do preparo do solo para o plantio da safra seguinte). Destaca-se que as parcelas instaladas no período de entressafra, permaneceram fixas até o final da pesquisa. Pois não havia atividade de revolvimento do solo nesse período. Para o cálculo da rugosidade superficial de cada mensuração foi utilizada a equação 2 : 


$$
R s=\frac{A i-A f}{A i} * 100 \quad \text { (equação 2) }
$$

Em que:

Rs = Rugosidade Superficial (\%);

$\mathrm{Ai}=$ Altura inicial $(\mathrm{cm})$;

Af $=$ Altura final $(\mathrm{cm})$.

\subsection{Retenção de água}

O resultado da rugosidade foi utilizado para estimar a retenção de água (Depth storage) em cada campanha, através da adaptação da equação proposta por Auerswald (1992) (equação 3). Destaca-se que a retenção de água da superfície do solo torna-se de grande importância para a dinâmica dos processos erosivos.

$$
D=\exp (-6.66+0,27 * R s) \quad \text { (equação } 3 \text { ) }
$$

Em que:

$\mathrm{D}=$ Retenção de água $(\mathrm{mm})$;

$\mathrm{R}=$ Rugosidade superficial (\%).

\subsection{Umidade superficial do solo}

A umidade do solo foi coletada com auxílio de uma sonda com sensor de umidade modelo "espeto", que quando introduzida no solo registra os valores de umidade e transmite para um Datalogger, que faz o registro dos dados. Para a coleta de dados de umidade foi utilizado um fio de nylon graduado e colocado de forma transversal entre os camalhões (Figura 4) e a cada 10 centímetros de distância foram realizadas as coletas de umidade sempre na mesma profundidade $(0$ a $10 \mathrm{~cm})$. Na entressafra, foram construídos perfis transversais com as mesmas distâncias daqueles dos períodos da safra, porém sem camalhões. Os procedimentos de coleta foram os mesmos em ambos os períodos.

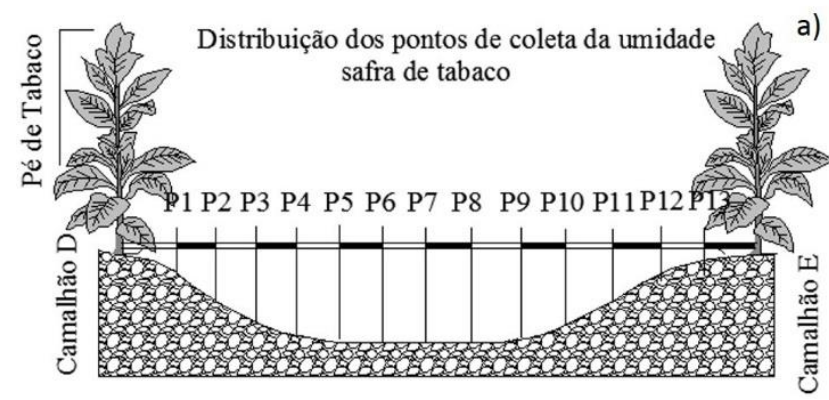

a)

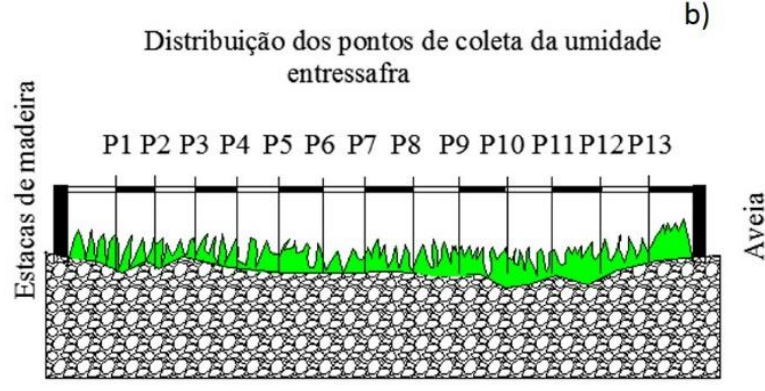

Figura 4: procedimento de coleta dos dados de umidade do solo de forma transversal; a) coleta da umidade no período de safra; b) coleta da umidade na entressafra do tabaco.

Fonte: Antoneli et al. (2016).

Nota: $\mathrm{Pn}$ - refere-se ao ponto de coleta, no caso foram 13 pontos, pois o intervalo entre os camalhões era de 1,3 metros de largura. Já na entressafra repetimos a mesma distância e os mesmos procedimentos de coleta. 
Foram realizados dez perfis em cada campanha de coleta. As coletas ocorreram quando a umidade do solo indicava capacidade de campo normal, ou seja, entre oito a dez dias após a última precipitação pluviométrica. As campanhas foram realizadas mensalmente, seguindo o mesmo protocolo de coleta da microtopografia. As campanhas de coleta foram realizadas sempre nos mesmos locais tanto na safra quanto na entressafra.

\subsection{Análise dos dados}

Os dados coletados foram tabulados e utilizados para na execução da estatística descritiva (soma, média e desvio padrão), para descrever as variáveis mensuradas. A significância estatística da comparação de médias entre os grupos foi conduzida pelo teste de Tukey, menor que $5 \%$ de significância. Os procedimentos estatísticos foram realizados usando o pacote de software Statistica 6.0.

Os dados foram representados em gráficos de box plot com as respectivas significâncias. Já para a representação da dinâmica microtopográfica os valores encontrados foram espacializados através do programa computacional Surfer 8.0.

\section{Resultados}

\subsection{Calendário agrícola}

O calendário das atividades agrícolas permite cruzar as informações por período em uma área agrícola que está sob o domínio de um determinado tipo de uso. Através das informações obtidas do calendário agrícola, foi possível observar a mudança na rugosidade superficial da área com cultivo de tabaco (Quadro 1).

Durante o ano, observou-se as variações nas atividades desenvolvidas na área de tabaco. Na safra do tabaco (setembro a fevereiro) foram realizadas trinta e oito atividades e deste total, nove atividades foram de revolvimento do solo. Todas as atividades de revolvimento do solo foram realizadas entre setembro e novembro, período de desenvolvimento do tabaco.

Quando iniciou a colheita do tabaco (dezembro), o agricultor deixou de revolver o solo, no entanto, o número de atividades permaneceu alto. Durante a colheita do tabaco (dezembro a fevereiro) foram realizadas dez colheitas, com intervalo de nove dias em média entre cada colheita (Antoneli et al., 2016). O agricultor retira em média três folhas por pé de tabaco em cada colheita (dependendo da maturação das folhas) (Antoneli, Thomaz, 2014). Durante a colheita do tabaco, o agricultor realiza outras atividades como desbrota e aplicação de agrotóxicos.

$\mathrm{Na}$ entressafra foram realizadas seis atividades, deste total, cinco foram de revolvimento do solo, sendo uma para revolver os restos da cultura do tabaco (março) e as outras três no início do preparo do solo para o cultivo do tabaco (agosto). A atividade restante está relacionada à semeadura da cobertura vegetal. 
Quadro 1: Atividades agrícolas desenvolvidas ao longo do ano em áreas de cultivo do tabaco.

\begin{tabular}{|c|c|c|c|c|c|c|c|c|c|c|c|c|}
\hline \multirow{7}{*}{$\begin{array}{l}\text { Atividades } \\
\text { Agrícolas }\end{array}$} & \multicolumn{6}{|c|}{ Safra } & \multicolumn{6}{|c|}{ Entressafra } \\
\hline & Set & Out & Nov & Dez & Jan & Fev & Mar & Abr & Mai & Jun & Jul & Ago \\
\hline & \multicolumn{12}{|c|}{$\begin{array}{l}\text { Transplante do tabaco e revolvimento do solo para limpeza das ervas daninhas; } \\
\text { intensificação das atividades de revolvimento do solo. }\end{array}$} \\
\hline & & & & \multicolumn{9}{|c|}{$\begin{array}{l}\text { Colheita do tabaco, sem revolvimento do solo. Aumento da } \\
\text { trafegabilidade. }\end{array}$} \\
\hline & & & & & & & \multicolumn{6}{|c|}{$\begin{array}{l}\text { Aração da terra; plantio de cobertura de } \\
\text { inverno. Redução das atividades. }\end{array}$} \\
\hline & & & & & & & & \multicolumn{5}{|c|}{$\begin{array}{l}\text { Solo agrícola coberto por forragem de } \\
\text { inverno; sem revolvimento do solo. }\end{array}$} \\
\hline & & & & & & & & & & & & $\begin{array}{l}\text { Preparo } \\
\text { do solo } \\
\text { (constru- } \\
\text { ção dos } \\
\text { cama- } \\
\text { lhões) }\end{array}$ \\
\hline Atividades* & 6 & 8 & 7 & 5 & 7 & 4 & 3 & 0 & 0 & 0 & 0 & 3 \\
\hline Rev. Solo** & 2 & 4 & 3 & 0 & 0 & 0 & 2 & 0 & 0 & 0 & 0 & 3 \\
\hline Precipitação & 124 & 179 & 246 & 207 & 164 & 119 & 187 & 154 & 212 & 139 & 108 & 64 \\
\hline
\end{tabular}

* Refere-se ao número de atividades que o agricultor desenvolveu na lavoura.

** Refere-se ao número de vezes que o agricultor revolveu o solo

Fonte: autores (2020)

\subsection{Exposição e umidade superficial do solo}

Os maiores índices de exposição do solo foram observados durante o período de revolvimento (Figura 5A), que se resume ao preparo do solo para a semeadura da cobertura vegetal de inverno (março e abril), preparo do solo para a construção dos camalhões (agosto), transplante do tabaco (setembro) e nos meses seguintes de desenvolvimento da planta do tabaco (setembro, outubro e novembro).

A umidade do solo durante a safra do tabaco foi homogénea, exceto o mês de setembro, início do plantio (Figura 5B). Já na entressafra a umidade foi aumentando à medida que a exposição do solo foi reduzindo.

No preparo do solo, tanto para o cultivo do tabaco quanto para a semeadura de inverno, a exposição média foi de $95 \%$. Com o desenvolvimento da planta do tabaco, a exposição do solo foi diminuindo, assim como após o plantio da cobertura vegetal de inverno. 

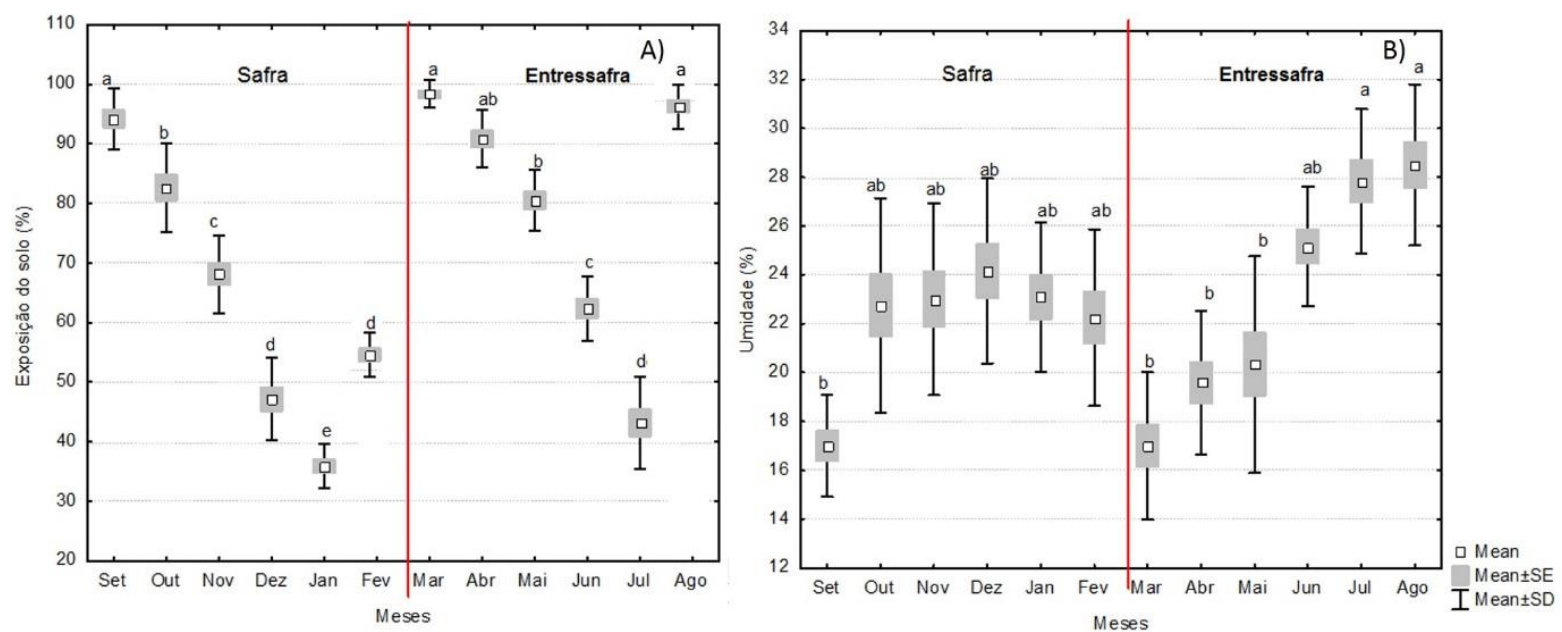

Figura 5: A) Exposição do solo na safra e entressafra do tabaco; B) umidade do solo na safra e entressafra do tabaco.

Nota: As letras iguais não diferem estatisticamente entre si à nível de $5 \%$ de probabilidade pelo teste de Tukey.

Fonte: Autores (2020)

\subsection{Mudança microtopográfica da superfície do solo}

As atividades desenvolvidas ao longo do ano nas áreas utilizadas para o cultivo de tabaco promoveram mudanças microtopográficas nas superfícies dos solos (Figura 6). Ao término da colheita (março) foi realizado o revolvimento do solo a fim de eliminar as soqueiras do tabaco (restos de cultura), destruição dos camalhões e preparo do solo para semeadura da adubação verde, que permaneceu em desenvolvimento até meados de julho ou início de agosto. A utilização do escarificador promoveu a destruição dos camalhões uniformizando a superfície.

Alguns dias antes do transplante das mudas de tabaco foi realizada a construção dos camalhões, os quais tem a finalidade de criar superfícies mais drenadas e areadas. Ao longo do cultivo tradicional os camalhões foram revolvidos e reconstruídos parcialmente nos processos de descompactação ou eliminação de ervas daninhas.

Ao término do mês de agosto ou início de setembro foi realizada a construção dos camalhões, os quais apresentaram em média $30 \mathrm{~cm}$ de altura e serviram como base para receber as mudas do tabaco. Esses "amontoados de terra" ficaram presentes até o término da colheita do tabaco. Cabe ressaltar, que a exposição aos efeitos pluvioerosivos, atividades agrícolas e a trafegabilidade promovem o rebaixamento destes camalhões com o passar dos meses. 


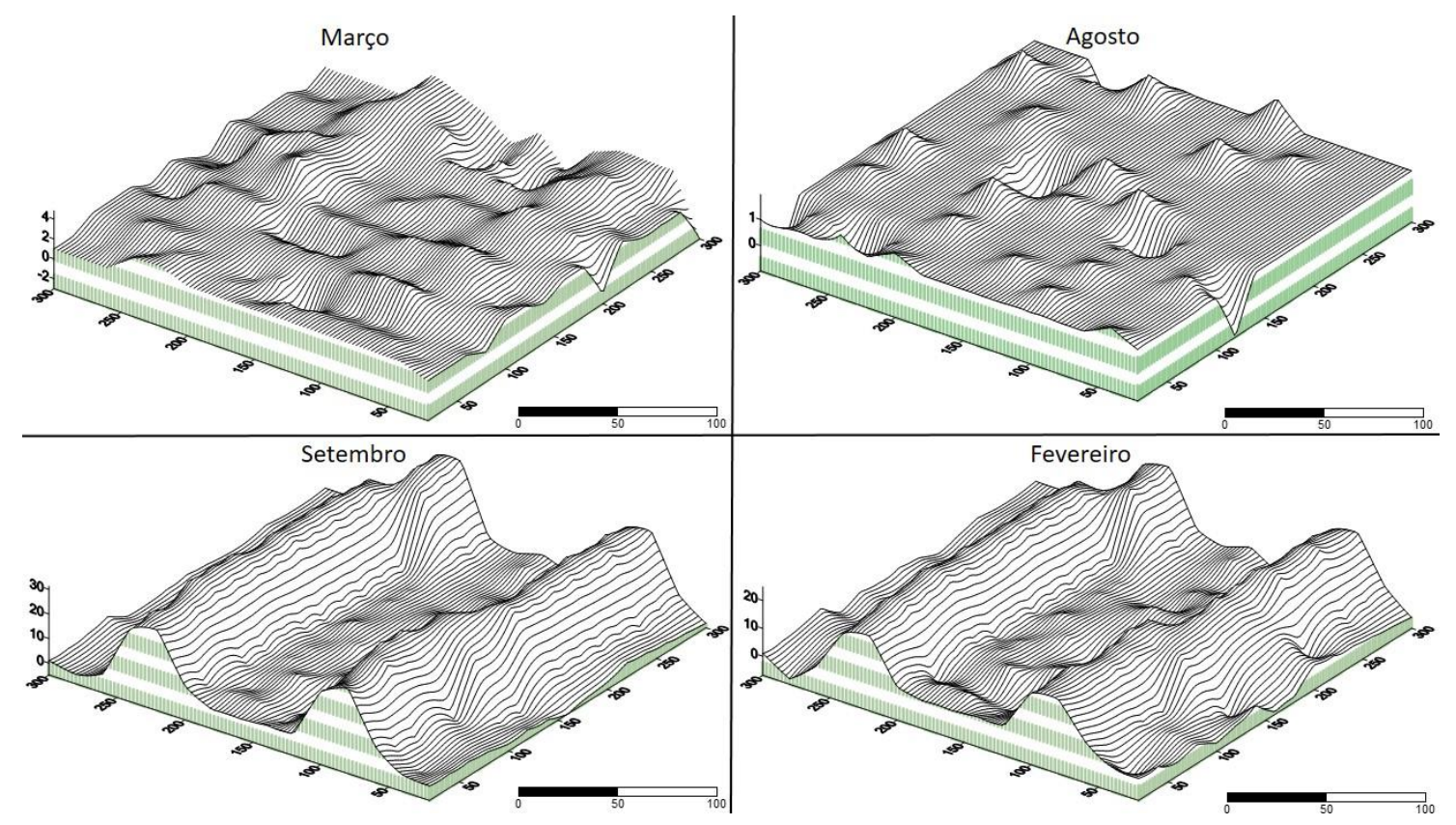

Figura 6: Mudança microtopográfica superficial no solo cultivado com tabaco.

Fonte: Autores (2020)

\subsection{Rugosidade superficial e retenção de água}

Todas as atividades realizadas nas áreas agrícolas acabam contribuindo com a mudança na rugosidade superficial, principalmente em plantio convencional (Figura 7A). As atividades desenvolvidas na safra e entressafra do tabaco indicaram variações significativas na mudança micropografica indicando diferentes valores de rugosidade superficial. A mudança na rugosidade superficial pode interferir na retenção de água no solo (Figura 7B).
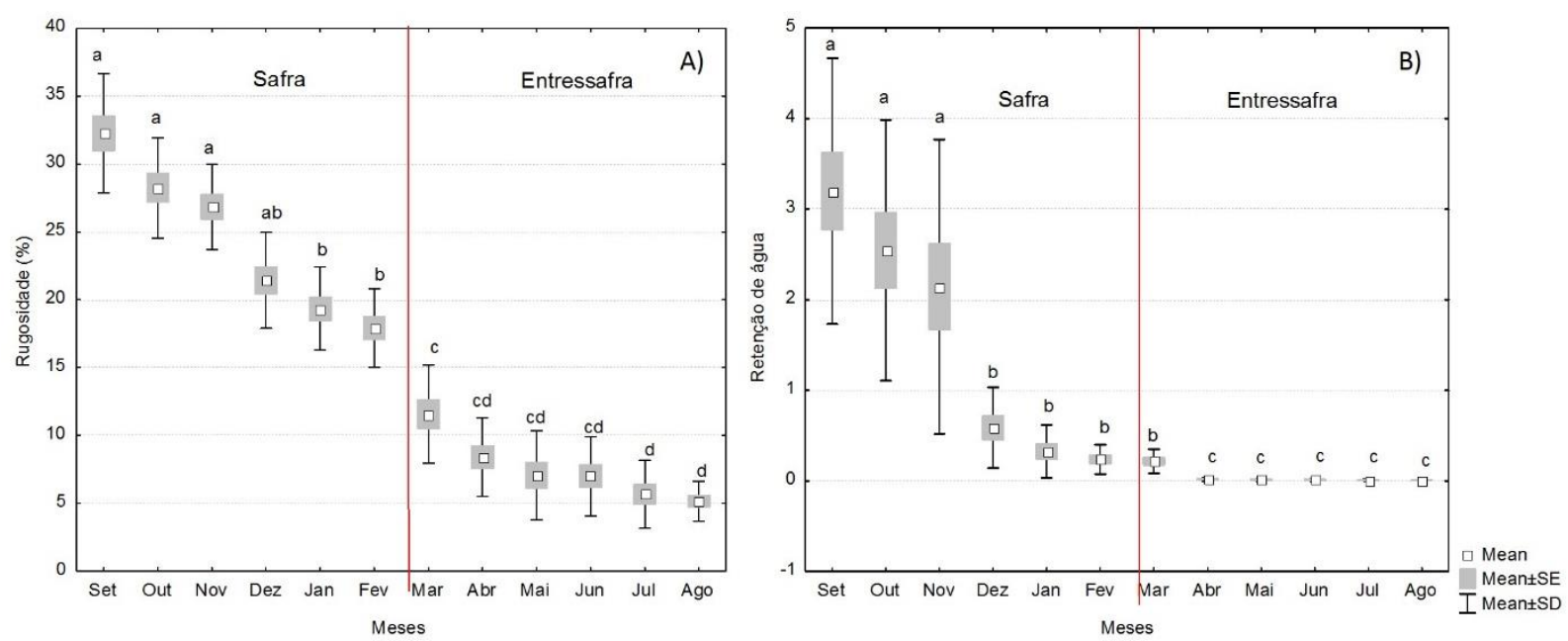

Figura 7: A) rugosidade superficial na safra e entressafra; B) retenção de água na superfície do solo na safra e entressafra.

Nota: As letras iguais não diferem estatisticamente entre si a nível de $5 \%$ de probabilidade pelo teste de Tukey.

Fonte: Autores (2020) 
O mês de setembro indicou maior rugosidade superficial (média de 32\%) e foi reduzindo ao longo do cultivo, sendo que no mês de fevereiro (término do cultivo) a rugosidade superficial foi de $17 \%$. No mês de março o agricultor removeu os camalhões e os restos da cultura do tabaco, indicando assim uma rugosidade de $12 \%$. Durante os meses de entressafra, a rugosidade superficial foi reduzindo.

Algumas variáveis indicaram alta correlação (Tabela 1), no entanto, as maiores correlações foram observadas no período de entressafra.

Tabela 1: Coeficiente de correlação de Pearson entre os parâmetros analisados.

\begin{tabular}{|c|c|c|c|c|c|c|}
\hline & \multicolumn{6}{|c|}{ Safra } \\
\hline & Chuva & $\begin{array}{c}\text { Exposição } \\
\text { do solo }\end{array}$ & $\begin{array}{l}\text { Rugosi- } \\
\text { dade }\end{array}$ & $\begin{array}{l}\text { Umida- } \\
\text { de }\end{array}$ & $\begin{array}{r}\text { Retenção } \\
\text { de água }\end{array}$ & $\begin{array}{l}\text { Revolvimen- } \\
\text { to do solo }\end{array}$ \\
\hline Chuva & 1,000 & & & & & \\
\hline Exposição solo & $0,254^{*}$ & 1,000 & & & & \\
\hline Rugosidade & $-0,197^{*}$ & $0,625^{\star \star *}$ & 1,000 & & & \\
\hline Umidade & $0,387^{* *}$ & $0,573^{* *}$ & $0,736^{* * *}$ & 1,000 & & \\
\hline Retenção de água & $0,278^{* *}$ & $0,247^{*}$ & $0,846^{\star * *}$ & $0,531^{* *}$ & 1,000 & \\
\hline \multirow[t]{2}{*}{$\begin{array}{c}\text { Revolvimento do } \\
\text { solo }\end{array}$} & $0,578^{* *}$ & $0,469^{\star *}$ & $0,835^{* * *}$ & $0,469^{* *}$ & 0,761 & 1,000 \\
\hline & \multicolumn{6}{|c|}{ Entressafra } \\
\hline Chuva & 1,000 & & & & & \\
\hline Exposição do solo & $0,168^{*}$ & 1,000 & & & & \\
\hline Rugosidade & $0,231^{*}$ & $0,876^{\star * *}$ & 1,000 & & & \\
\hline Umidade & $0,438^{* *}$ & $0,896^{* * *}$ & $0,846^{\star * *}$ & 1,000 & & \\
\hline Retenção de água & $0,178^{* *}$ & $0,417^{\star *}$ & $0,732^{* * *}$ & $0,636^{* * *}$ & 1,000 & \\
\hline $\begin{array}{l}\text { Revolvimento do } \\
\text { solo }\end{array}$ & $0,214^{*}$ & $0,883^{* * *}$ & $0,893^{\star \star *}$ & $0,138^{\star * *}$ & $0,341^{* *}$ & 1,000 \\
\hline
\end{tabular}

Durante a safra, observa-se maior correlação entre a rugosidade com umidade, exposição e revolvimento do solo. $\mathrm{Na}$ entressafra, apenas a chuva indicou baixa correlação com os demais parâmetros. A maior correlação na entressafra foi observada entre a umidade do solo com a exposição $(0,896, p<0.001)$ e entre 0 revolvimento do solo com a rugosidade $(0,893, p<0.001)$.

\section{Discussão}

Muitos fatores têm levado ao aumento das áreas de cultivo do tabaco nas últimas décadas nas pequenas fazendas. Dentre esses fatores estão a garantia da venda da produção através de contratos firmados entre os agricultores e as empresas (Kienle et al., 2015), mesmo antes da produção; alta produtividade quando comparado com outros tipos de cultura; estabilidade de preços, incentivos de insumos, lucro, dentre outros (Hasan, 2019).

Essas características potencializam o cultivo do tabaco nas pequenas fazendas que em sua maioria utilizam a mão-de-obra familiar e pouca mecanização (Antoneli et al., 2018). O uso de implementos rudimentares de tração animal (cavalos e bois) facilita a transformação das locais com restrições ao uso agrícola em áreas agricultáveis. 
Portanto, a falta de mecanização e as restrições ao uso contribuem para que o agricultor cultive o tabaco com poucas práticas conservacionistas e com uso do plantio convencional. Como as fazendas de tabaco geralmente são pequenas, não há rodízio de terras e o cultivo excessivo é considerado um dos principais tipos de degradação do solo (Qin et al., 2017).

A agricultura efetuada com plantio convencional se caracteriza pelo revolvimento e exposição do solo. Este revolvimento interfere nas condições da superfície do solo alterando a rugosidade superficial que afeta a redistribuição da água da chuva (Novara et al., 2011; Balota et al., 2016) interferindo na dinâmica hidrológica de uma determinada encosta (Zhao et al., 2018).

O preparo do solo tanto para o plantio do tabaco (agosto) quanto para a semeadura da cobertura vegetal de inverno (março) indicaram os maiores valores de exposição do solo e os menores valores de umidade superficial do solo. No entanto, a rugosidade superficial foi diferente entre os dois períodos devido às características de cada plantio.

A variação da umidade do solo na entressafra foi condizente com a exposição, mas na safra, a umidade foi similar em todas as mensurações, exceto no mês de setembro. A homogeneidade da umidade durante a safra do tabaco pode ser atrelada a característica morfológica da planta do tabaco que direciona parte da água captada pelas folhas para o centro da entrelinha (Antoneli et al., 2017). Essa dinâmica potencializa a entrada de água na entrelinha que devido a sua morfologia torna-se um canal efêmero, com fluxos longos e compactados pelas atividades, o que pode gerar uma grande quantidade de escoamento superficial e erosão (Antoneli, Thomaz, 2014), mesmo em terreno plano (Slattery et al.,1997).

A construção dos camalhões acaba amontoando solo desagregado e muitos blocos (torrões) que potencializam a rugosidade do solo, contribuindo com a retenção de água. Foi observado nas primeiras chuvas que muitos desses blocos (torrões) foram se desestruturando e preenchendo as microdepressões deixadas na entrelinha.

Durante o revolvimento do solo, das entrelinhas através de equipamentos rudimentares e revolvimento de parte dos camalhões por meio da capina manual, esses blocos se desestruturaram, tornando-se solo desagregado. A rugosidade do solo nesse período se manteve elevada porque após o revolvimento da entrelinha e desestruturação de parte do camalhão, o agricultor reconstituiu o próprio camalhão na sequência.

O revolvimento do solo nos primeiros meses de cultivo do tabaco manteve o solo descompactado, permitindo maior taxa de infiltração de água (Zaluski, Antoneli, 2012). Este revolvimento pode misturar as partículas do solo e assim, levar a uma distribuição mais uniforme das propriedades físicas do solo (Liu et al., 2018).

Durante a colheita do tabaco a rugosidade superficial da entrelinha foi reduzindo, devido a falta de remobilização do solo e do aumento da trafegabilidade (tabelax) tornando a superfície mais lisa e compactada (Antoneli et al., 2016), reduzindo a 
retenção de água e potencializando o escoamento superficial (Zhao et al., 2013; Zhao et al., 2018).

Esta condição permite que o cultivo de tabaco apresente índices elevados de perdas de solo, alterando as condições hidrológicas dessas áreas. Geralmente nas pequenas fazendas há uma intensificação do uso do solo e, em muitos casos, não são respeitadas as leis ambientais. Como isso o plantio de tabaco adentra em áreas de APP (Áreas de Preservação Permanente) reduzindo a eficiência da zona ripária na taxa de transferência de sedimentos das encostas para os corpos hídricos (Kuglerová et al., 2014), interferindo na qualidade da água (Ranalli et al., 2010).

A cobertura vegetal de inverno foi reduzindo a rugosidade e a exposição do solo, aumentando assim a umidade superficial, que resulta na redução das perdas de água e solo. Antoneli et al. (2018), observaram que a perda de solo foi 4,5 vezes inferior na entressafra sob plantio de aveia quando comparado com a safra do tabaco.

Portanto, o revolvimento do solo alterou a rugosidade superficial, que, por conseguinte, indicou alta correlação com a retenção de água. A alta rugosidade superficial potencializa a infiltração de água, pois as microdepressões retêm água e sedimentos, reduzindo o escoamento superficial (Keesstra et al., 2012).

\section{Conclusão}

A rugosidade superficial do solo sofreu a ação das atividades agrícolas durante a safra do tabaco. Os maiores índices de rugosidade foram observados no início do cultivo e durante o revolvimento do solo. $\mathrm{Na}$ entressafra a rugosidade do solo foi diminuindo devido aos processos pluvioerosivos que acabam preenchendo as irregularidades microtopográficas da superfície do solo.

Os índices de rugosidade indicaram alta correlação com a retenção de água, na safra e entressafra, enquanto a umidade do solo na safra sofreu influência dos estágios da planta do tabaco. No período de maior cobertura do solo, houve aumento da umidade na entrelinha e redução da umidade no camalhão. A distribuição irregular da umidade deveu-se às características das folhas do tabaco que interceptaram a água da chuva que chegaria ao solo do camalhão e redirecionaram para a entrelinha.

O método de batimetria se mostrou eficiente para identificar as mudanças micropotográficas no solo decorrentes das atividades agrícolas. No entanto, o pesquisador precisa tomar alguns cuidados na instalação das parcelas, para que as coletas sejam realizadas sempre no mesmo local.

A forma de cultivo e as atividades diárias realizadas no plantio de tabaco mostraram que o plantio convencional deve ser evitado ao máximo. Essas atividades alteram a estrutura da superfície do solo, desencadeando processos de degradação do solo. Recomenda-se que 0 agricultor tome algumas medidas conservacionistas: a) construção do camalhão antes da semeadura de inverno (abril) e que o tabaco seja transplantado sob uma cobertura morta, desenvolvendo assim uma espécie de cultivo mínimo; b) redução do revolvimento do solo durante os primeiros estágios da cultura. 


\section{Bibliografia}

Antoneli, V. (2011). Dinâmica do uso da terra e a produção de sedimentos em diferentes áreas fontes na bacia hidrográfica do Arroio Boa Vista- Guamiranga-PR. Tese de Doutorado em Geografia. Curitiba. UFPR.

Antoneli, V., Thomaz, E. L. (2014). Perda de solo em cultivo de tabaco sob diferentes formas de cultivo na região Sudeste do Paraná. Revista Brasileira de Geomorfologia, 15(3), 455469. http://dx.doi.org/10.20502/rbg.v15i3.534

Antoneli, V., Bednarz, J. A., de Jesus, F. C. (2016). Avaliação da umidade superficial do solo em cultivo de tabaco em plantio direto e convencional na região Sudeste do Paraná. Caminhos de Geografia, 17(59), 51-64. https://doi.org/10.14393/RCG175904

Antoneli, V., de Jesus, F. C., Bednarz, J. A., (2017). Resistência do solo em cultivo de tabaco com diferentes formas de manejo na região sudeste do Paraná. Revista Brasileira de Geomorfologia, 18(2), 363-377. http://dx.doi.org/10.20502/rbg.v18i2.1146

Antoneli, V., Lenatorvicz, H. H., Bednarz, J. A., Pulido-Fernández, M., Brevik, E. C., Cerdà, A., Rodrigo-Comino, J. (2018). Rainfall and land management effects on erosion and soil properties in traditional Brazilian tobacco plantations. Hydrological Sciences Journal, 63(7), 1008-1019. https://doi.org/10.1080/02626667.2018.1472379

Auerswald, K. (1992). Changes in surface roughness during erosive rains. Lehrstuhl für Bodenkunde, TU München, D-8050.

Balota, E. L., Machineski, O., Honda, C., Yada, I. F. U., Barbosa, G. M. C., Nakatani, A. S., Coyne, M. S. (2016). Response of arbuscular mycorrhizal fungi in different soil tillage systems to long-term swine slurry application. Land Degrad. Dev., 27(4), 1141-1150. https://doi.org/10.1002/ldr.2304

Choudhury, S. G., Srivastava, S., Singh, R., Chaudhari, S. K., Sharma, D. K., Singh, S. K., Sarkar, D. (2014). Tillage and residue management effects on soil aggregation, organic carbon dynamics and yield attribute in rice-wheat cropping system under reclaimed sodic soil. Soil Tillage Res., 136, 76-83. https://doi.org/10.1016/..still.2013.10.001

Dabney, S. M., Yoder, D. C., Vieira, D. A. N., Bingner, R. L. (2011). Enhancing RUSLE to include runoff-driven phenomena. Hydrol. Process, 25(9), 1373 - 1390. https://doi.org/10.1002/hyp.7897

Dalla Rosa, J., Cooper, M., Darboux, F., Medeiros, J. C. (2012). Soil roughness evolution in different tillage systems under simulated rainfall using a semivariogram-based index. Soil Tillage Res., 124, 226-232. https://doi.org/10.1016/i.still.2012.06.001

Dan, S., Zhang, W., Lin, Y., Lui, Z. (2018). Soil erosion and water retention varies with plantation type and age. Forest Ecology and Management, 422, 1-10. https://doi.org/10.1016/i.foreco.2018.03.048

DERAL - Departamento de Economia Rural (2017). Prognóstico Fumo. Secretaria da Agricultura e do Abastecimento do Estado do Paraná - SEAB. Consultado em 10 de abril de 2018

em: http://www.agricultura.pr.gov.br/arquivos/File/deral/Prognosticos/2018/Fumo 2017 18.pdf

EMBRAPA (1997). Embrapa Solos. Consultado em 29 abril de 2019 em: https://www.embrapa.br/solos 
FAO, Food and Agriculture organization of the United Nations. (2015). Status of the Word's soil resources - Main Report. FAO and ITPS. Consultado em 15 de maio 2018 em: http://www.fao.org/3/a-i5199e.pdf

Fernandez, O. V. Q., Sander, C., Rebelatto, G. E. (2001). Análise quantitativa de seções transversais em canais fluviais. Revista Brasileira de Geomorfologia, 2(1), 85- 92.

Filho, A. G., Pessoa, A. C. dos S., Strohhaecker, L., Helmich, J. J. (2000). Preparo convencional e cultivo mínimo do solo na cultura de mandioca em condições de adubação verde com ervilhaca e aveia preta. Ciência Rural, 30, 6, 953-957. https://doi.org/10.1590/S0103-84782000000600005

Fontana, C. R., Lima, W. de P., Ferraz, S. F. de Barros. (2007). Avaliação da remoção de sedimentos pela operação de nivelamento de estradas florestais. Sci. For., 76, 103-109.

Hansen, B., Schjønning, P., E. Sibbesen, E. (1999). Roughness indices for estimation of depression storage capacity of tilled soil surfaces. Soil Tillage Res., 52(1-2), 103-111. https://doi.org/10.1016/S0167-1987(99)00061-6

Hasan, K. M. (2019) Factors influencing farmers turning into tobacco cultivation in the Khulna division of Bangladesh: an empirical study. Tobacco prevention \& cessation, 5 (Supplement), A128. https://doi.org/10.18332/tpc/105152

IAPAR - Instituto Agronômico do Paraná. (1995). Caracterização da Agricultura no Paraná. $45 p$.

Keesstra, S. D., Geissen, V., Mosse, K., Piiranen, S., Scudiero, E., Leiatra, M. (2012) Soil as a filter for groundwater quality. Current Opinion in Environmental Sustainability, 4(5), 507516. https://doi.org/10.1016/j.cosust.2012.10.007

Kienle, U., Manos, U., Jungbluth, T. B. (2015). Alternatives to Tobacco cultivation-Towards an evidence based approach. Land Use Policy, 45, 199-203. https://doi.org/10.1016/j.landusepol.2015.01.009

Kuglerová, L., Ågren, A., Jansson, R., Laudon, H. (2014) Towards optimizing riparian buffer zones: Ecological and biogeochemical implications for forest management. Forest Ecology and Management, 334, 74-84. https://doi.org/10.1016/j.foreco.2014.08.033

Melquiades, F. L., Bastos, R. O., Andreoni, L. F. S., Thomaz, E. L., Antoneli, V. (2018). Coupling soil transfer from hillslope to riparian zone through natural fingerprint in a catchment with tobacco crop. Journal of Soils and Sediments, 19, 1928-1936. https://doi.org/10.1007/s11368-018-2181-2

Merten, G. H., Minella, J. P. G. (2006). Impact on sediment yield due to the intensification of tobacco production in a catchment in Southern Brazil. Ciência Rural, 36(2), 669-672. http://dx.doi.org/10.1590/S0103-84782006000200050

Montgomery, D. R. (2007). Soil erosion and agricultural sustainability. Proc. Natl. Acad. Sci. U. S. A., 104, 13268-13272.

Novara, A., Gristina, L., Saladino, S. S., Santoro, A., Cerdà, A. (2011). Soil erosion assessment on tillage and alternative soil managements in a sicilian vineyard. Soil. Tillage Res., 117, 140-147. https://doi.org/10.1016/i.still.2011.09.007 
Qin, S., Yeboah, S., Cao, L., Zhang, J., Shi, S., Liu, Y. (2017). Breaking continuous potato cropping with legumes improves soil microbial communities, enzyme activities and tuber yield. PLoS One, 12(5), e0175934. https://doi.org/10.1371/journal.pone.0175934

Ranalli, A. J., Macalady, D. L. (2010). The importance of the riparian zone and in-stream processes in nitrate attenuation in undisturbed and agricultural watersheds - A review of the scientific literature. Journal of Hydrology, 389(3-4), 406-415. https://doi.org/10.1016/j.jhydrol.2010.05.045

Schillinger, W. F., Kennedy, A. C., Young, D. L. (2007). Eight years of annual no-till cropping in Washington's winter wheat-summer fallow region. Agric. Ecosyst. Environ., 120 (2-4), 345-358. https://doi.org/10.1016/i.agee.2006.10.017

Slattery, M. C., Burt, T. P., Gares, P. A. (1997). Dramatic Erosion of a Tobacco Field at Vanceboro, North Carolina. Southeastern Geographer, 37(1), 85-90. https://doi.org/10.1353/sgo.1997.0002

Taconet, O., Ciarletti, V. (2007). Estimating soil roughness indices on a ridge-and-furrow surface using stereo photogrammetry. Soil and Tillage Research, 93(1), 64-76. https://doi.org/10.1016/i.still.2006.03.018

Torres-Rojo, J. M., Francisco-Cruz, C. A., Islas-Aguirre, J. F., Ramírez-Fuentes, G. A., PérezSosa, L. (2020). A scale invariant model for the expansion of agricultural land and government spending on the agricultural sector. Land Use Policy. 92, 104438. https://doi.org/10.1016/j.landusepol.2019.104438

Wood, S. D., Worsham, A. D. (1986). Reducing soil erosion in tobacco fields with no-tillage transplanting. Journal of Soil and Water Conservation, 41(3), 193-196.

Zaluski, P., Antoneli, V. (2014). Variabilidade na infiltração da água no solo em área de cultivo de tabaco na região Centro-Sul do Paraná. Caderno de Geografia, 24(41), 34-47. https://doi.org/10.5752/P.2318-2962.2014v24n41p34

Zhao, L., Hou, R., Wu, F., Keesstra, S. (2018). Effect of soil surface roughness on infiltration water, ponding and runoff on tilled soils under rainfall simulation experiments. Soil and Tillage Research, 179, 47-53. https://doi.org/10.1016/..still.2018.01.009

Zhao, L., Wang, L., Liang, X., Wang, J., Wu, F. (2013). Soil Surface Roughness Effects on Infiltration Process of a Cultivated Slopes on the Loess Plateau of China. Water Resources Management, 27(14), 4759-4771. https://doi.org/10.1007/s11269-013-0428-7

Artigo recebido em / Received on: 21/10/2020

Artigo aceite para publicação em / Accepted for publication on: 08/12/2020 